\title{
"Konfettaskar" och "typografiska läckerbitar" eller funktionalistisk formgivning? om Eva Billow som bilderbokskonstnär och grafiker
}

http://urn.kb.se/resolve?urn=urn:nbn:se:sbi-28

Citation: Nordic Journal of ChildLit Aesthetics, Vol. 2, 2011 DOI: 10.3402/

blft.v2i0.5832

Abstract: Eva Billow as picture book artist and graphic designer.

The 1940's and 50's was a dynamic period for the Nordic picturebook. There is a general aspiration to explore picture book aesthetics, a need to find imagery and expressions capturing a new era. In my article, I will discuss how these ideas are expressed in the illustrator and graphic artist Eva Billow's picture books. Her illustration style is originated in a modernist tradition of simplicity, clarity and typographic precision. Also, an idea about books as an art form is evident through her production. Eva Billow's production covers a wide field of graphic design, from picture books, cartoons and illustrations to book art, posters and advertisements. I will discuss Billow's use of aesthetics that can be related to functionalist ideas and will further place this approach in a larger context in the history of Swedish graphic design. The general interest in graphic design and new printing techniques among picturebook illustrators can also be seen as a part of a tendency within Nordic Modernism where the artist aspired to make arts a part of the society. But the appeal for the picturebook among the young Nordic artists and authors, prior and after the Second World War, also expresses an inter-artistic tendency, where the limits between different forms of art are explored.

Keywords: picturebook, graphic design, functionalism, modernism, illustration history, literary criticism

Kalligrafen, formgivaren och bilderboksförfattaren Eva Billows (1902-1993) produktion är en del av en dynamisk bilderboksepok under 1940- och 1950-talen i Sverige. Parallellt med sin närmast fyrtioåriga karriär som lärare vid Tekniska skolan (nuvarande 
Konstfack) arbetade Billow ständigt med grafisk formgivning: reklam, bokprodukter, kalligrafi, skolplanscher och olika typer av trycksaker. Förutom ett dussintal egna bilderböcker, illustrerade och kalligraferade Billow ett antal bilderböcker och romaner av andra författare och publicerade serien "Kajsa och Snurran" i Svenska Journalen 1925-1961. I denna artikel kommer jag att presentera några av de frågeställningar som ligger $\mathrm{i}$ fokus för mitt forskningsprojekt kring Eva Billows konstnärskap. Med tanke på Billows utbildning och yrkesverksamhet som grafiker kommer jag att förutom den barnlitterära kontexten undersöka hur hennes estetik formas i förhållande till den grafiska formgivningens och bokkonstens utveckling. Kopplingarna till formgivnings- och boktryckarbranchen blir dessutom betydelsefulla eftersom Billow i flera år samarbetade med sin make, grafikern Anders Billow. Hur tolkades Eva Billows estetik i sin samtid och, med utgångspunkt i receptionen av hennes produktion, hur kan hennes position beskrivas i förhållande till den övriga bilderboksmodernismen?

Ulla Bergstrand menar att Eva Billows böcker kännetecknas av "vänlig, stillsam humor" (Bergstrand 1985, 34). Hennes barnvärld beskrivs av Boel Westin som realistisk, "en snäll och trygg småstadsidyll, med motiv hämtade ur barnens vardag" (Westin 1985, 74). Helena Magnusson finner i sin avhandling att det mesta cirklar kring hemmet och familjen i Billows serier. Barnen avbildas sällan som en del av något större samhälle, inte heller skildras kamrater och skola, något som skiljer sig från samtida serier om barn i skolålder (Magnusson 2005, 139). Det lugna tempot liksom de vardagsrealistiska motivkretsarna karakteriseras av en saknad av kontroverser eller provokationer: "[i]nga märkvärdiga händelser, inga alltför starka protester mot $t$ ex vuxenvärldens lydnadskrav, bara lite oskuldsfulla 'hyss' ibland" skriver Bergstrand om Billows produktion (Bergstrand 1992, 85).

Även recensionerna av Billows bilderböcker betonar det lugna tempot och omsorgsfulla formspråket. I sina recensioner använder t.ex. Eva von Zweigberg återkommande nyckelord som "nätt", "lustig", "finurlig" och "söt" om Billows bilderböcker, även om hon genomgående betonar den höga kvalitén i bokhantverket. I recensionen av Många gratulationer på födelsedagen 1952 skriver von Zweigbergk som följer: "Eva Billows böcker är som alltid mycket vackra och typografiskt vårdade, så koketta och aptitliga som konfettaskar. Det är en behaglig sort, inte minst för små flickor, och de är späckade med små oväntade lustigheter" (von Zweigbergk 1952). Liknelsen med godsaker används även av Corinna, pseudonym för Greta 
Bolin, som beskriver Billows böcker som "typografiska läckerbitar" (Bolin 1951). Brita Schlyter i sin tur beskriver bilderboken Hittar du till smultronstället? som "söt och rolig", en "prydnad för vilket salongsbord som helst" (Schlyter 1954). Återkommande användning av vissa nyckelord är särskilt intressant i Greta Bolins recensioner i Svenska Dagbladet:

Vad det är skönt och befriande att hitta en barnbok, som är både vacker och vänlig! Här i Eva Billows nya bilderbok finns ingenting sofistikerat, ingenting tillgjort djupsinnigt, allt är okonstlat och barnsligt på rätt sätt. Det behövs sådana böcker också bland allt som är crazy och mer eller mindre ädelnonsens. Enkelt och naturligt - på rim - berättar Eva Billow om livets små händelser, ibland med en liten glimt av poetisk känsla [...] (Greta Bolins recension av Jag tycker mest om plättar i Svenska Dagbladet 1953).

Ord som "sofistikerat", "crazy" eller "ädelnonsens" används här i negativ bemärkelse. Året efter använder Bolin liknande formuleringar i sin recension av Hittar du till smultronstället?

Det känns befriande att då och då - det är alltför sällan - hitta en rar bilderbok, och med uttrycket rar menas nu vänlig atmosfär, glada, spontana påhitt och kultiverad smak i ord och bild. Man är ganska trött på alla fula och groteska figurer och på all den ansträngt sofistikerade roligheten - och det undras mig, om inte ungarna också är det. (Greta Bohlin, "Vackert, vänligt och lustigt för de små" i Svenska Dagbladet 1954)

Även här ställs det "vänliga", "glada" och "spontana" mot det "ansträngt sofistikerade".

Som bland annat Lena Kåreland har visat i Modernismen $i$ barnkammaren, finns det under 1940- och 1950-talet en uppenbar polarisering mellan olika tendenser inom barnlitteraturen (Kåreland 1999, 94-96). Både positivt och negativt laddade nyckelbegrepp och karakteriseringstermer används för att framhäva det som uppfattas som önskvärt eller negativt i böckerna. Men ordval och begrepp ger också uttryck åt motsättningarna mellan traditionalisterna och den yngre generationen. Dessa motsättningar är särskilt tydliga i den successiva nyorientering som sker efter 1945. Lena Kåreland påpekar att den goda smaken och den "kultiverade stilen" var rättesnören för bland annat von Zweigbergk och Bolin som företrädde en huvudsakligen traditionalistisk syn på barnlitteraturen (Kåreland 
1999, 71). En genomgång av recensioner av Eva Billows böcker visar samtidigt tydligt att de nya tankarna successivt började accepteras och att barnboksfältet förändras i mitten av 1950-talet. Exempelvis Bolin, som tidigare inte yttrat några reservationer gällande Billows böcker, uttrycker 1954 en viss tveksamhet inför hennes stil som Bolin befarar kan bli "alltför preciös" - en formulering som hon använder i två recensioner, såväl 1954 som 1955 och ett förbehåll som hon återkommer till 1957 i recensionen av Ta av dig mössan, Mårten! Här menar hon att Billows "manér går i den sirliga, litet gammaldags och pretiösa stilen" (Bohlin 1957).

Den huvudsakliga uppfattningen i samtida barnlitteraturkritik är alltså att Billows böcker står för sunda värderingar och en "kultiverad smak", kvalitet och hög hantverkskunnighet. Bland annat Lennart Hellsing, som i sin kritik av Billows böcker inte alltid var odelat positiv, kallade Billow för "den typografiska barnboksmästarinnan" i Aftonbladet 1951. Hennes böcker uppfattas i sin tid som representanter för den konstnärliga svenska kvalitetsbilderboken som allt oftare under 1950-talet ställs mot importerade massmarknadsböcker och "den amerikanska skräpimporten" (Schlyter 1954). Däremot ses hennes böcker inte nödvändigtvis som en del av den konstnärligt experimenterande "unga" bilderbokstrenden, som bland annat representeras av Lennart Hellsing och de illustratörer som samarbetade med honom, som Stig Lindberg eller Poul Ströyer. Snarast uppfattas hon av vissa kritiker närmast som en motpol till denna utveckling.

Den nyorientering som sker inom barnlitteraturen under 1940och 1950-talen rymmer dock flera utvecklingslinjer, vilket jag uppmärksammar i min avhandling Modernismens bilder (2008). Barnets roll i modernismen, liksom berörningspunkterna mellan barn- och vuxenlitteratur har uppmärksammats av flera forskare (Dusinberre 1987, Lloyd 1992, Westin 1993). Modernismen är en viktig del av den moderna bilderbokens estetik, men linjerna till språk och berättarformer går åt många olika håll, från bejakandet av det lekfulla och upproriska till funktionalistiska tankar om innehållets och formens samspel. Samtidigt blev bilderboken ett medel för att gestalta en modern barndom, något som även uttrycktes genom valet av illustrationstekniker som signalerade framåtanda och aktualitet. Tidiga danska bilderböcker som Arne Ungermanns och Hans Kirks Jørgens hjul (1932) eller Ungermanns illustrationer i Harald Lunds Toget: den sjove bog (1936) uttrycker en allmän dyrkan av rörelse, resande och fart, något som snart blir framträdande även i den svenska bilderboken. Liksom för många av danskarna blev bilderboken en plats 
för formexperiment för konstnärer som Tove Jansson, Egon MøllerNielsen eller Stig Lindberg. Deras bilderböcker är exempel på hur bilderboksmediet kunde bli en plats för nya uttryck via det naiva, expressiva eller surrealistiska. Parallellt med denna tendens uttrycks det även ett starkt intresse för det "primitiva" och livsdyrkande, ofta förknippat med det infantila, som i Jens August Schades och Hans Scherfigs Urskoven (1937), Egon Mathiesens Fredrik med bilen (1944) eller i Ingrid Vang Nymans illustrationer.

\section{Bilderboken som bokkonst}

Billows produktion sammanfaller med ovan nämnda dynamiska bilderboksepok i Norden, men bakgrunden och impulserna för hennes konstnärskap kan också spåras till den grafiska formgivningens och bokkonstens utveckling och den form av funktionalism som utvecklades inom svensk bokkonst från 1940-talet och framåt. Den närmast funktionalistiska tanke om stramhet, elegans och ändamålsenlighet liksom samspelet mellan innehåll och form som präglar Billows produktion ligger tydligt i linje med idéerna inom samtida grafisk formgivning. Men är det möjligt att prata om funktionalism inom bilderboken och, i så fall, vad får den för uttryck? Är föreställningar om Billows böcker som söta "konfettaskar" eller som föremål som "pryder vilket salongsbord som helst" förenliga med funktionalistiska idéer?

Det som framträder tydligt är att Billow framförallt formmässigt har en kompromisslös inställning till bilderboken som medium, något som stundtals har förbisetts på grund av böckernas snälla och trygga motivkretsar. Hennes bilderböcker kännetecknas av en enhetlig estetisk praktik som är genomtänkt in i minsta detalj. Samtidigt uttrycks här ett sökande efter nya uttrycksmedel och berättartekniker, även om detta sökande möjligen inte uttrycks på liknande sätt som hos några av de andra samtida bilderbokskonstnärerna. "Min ambition är att göra barnböcker, som närmar sig bokkonst, alltså en genomtänkt bokprodukt", berättar Eva Billow i en intervju med Corinna i Svenska Dagbladet 1961. Att utgångspunkten för arbetet är bokprodukten uttrycks även i hennes uttalande om sin arbetsprocess. Hon berättar att hon inleder arbetet med en provbok i miniatyr, stor som en tändsticksask, för att se "hur bilder och text gör sig på sidan" (Bolin 1961). Först efter det utförs illustrationer i original i större skala. Arbetssättet uttrycker en helhetssyn på boken. Att konstnären dessutom anser att bilderböcker ska fungera som "genomtänkta bokprodukter" signalerar ett funktionalistiskt tillvägagångssätt. 
Om man betraktar funktionalismen som en arbetsmetod snarare än en stilriktning framträder en grundläggande tanke om det funktionalistiskt framställda föremålet som skulle utformas utifrån sin funktion. I Nils G. Wollins Hemmet och den moderna smaken i Sverige (1928) placeras bokkonsten inom en kollektiv formkultur: "Som konstindustriell produkt kan den [bokkonsten] nämligen vara ett bärande uttryck för tidens demokratiska tendenser, vilka ju bland annat följa parollen: konsten för folket" (Wollin 1928, 229). Liknande tongångar finner vi inom barnlitteraturen: tanken om bilderboken som ett sätt att förmedla konst för barn ligger i tiden. Bland annat beskrev Lennart Hellsing barnboken som en "leksakslåda" där barnet plockar ut ord, ljud och bilder (Hellsing 1963, 43). Som en parallell utvecklingslinje, som blir betydelsefull för den svenska bilderbokens utveckling, är den nya danska bilderboken. Bland annat talar bilderbokskonstnären Egon Mathiesen redan 1934 om bilderböcker och illustrationer som "udbredelse af kunst", det vill säga spridning av konst (Mathiesen 1934, 9). Den konstnärliga utgångspunkten uttrycks hos Mathiesen som ett intresse för det primitiva, målande färger och abstraktion genom naivism: "en slags malerier for børn" som Vibeke Stybe beskriver Mathiesens bilderböcker (Stybe 1992, 64). Även om såväl Billows konstnärsroll som förhållningssätt till bilderboken skiljer sig markant från Mathiesens, är målet hos henne att skapa bilderböcker som närmar sig modern bokkonst. Den konstnärliga utgångspunkten hos Billow är primärt att skapa bokkonst, en genomtänkt, fulländad bokprodukt. Här görs egentligen inga anspråk på att bilderboken skulle fungera som länk till bildkonst utan det som framhävs istället är bilderboken som en del av den moderna bokkonsten. Det är en tanke som ligger i linje med demokratiska idéer om god konst och design som ska vara tillgängliga för alla med motton som "konst för folket" och "vackrare vardagsvaror" (Wickman 1995, 11).

Eva Billows make, konsthistorikern och formgivaren Anders Billow (1890-1964) var av stor betydelse för konstnärens yrkesverksamhet och konstnärliga utveckling. Mer än någon annan grafiker influerade han den moderna svenska bokformgivningen under framför allt 1930- och 1940-talen då han förnyade bokkonsten med sin funktionalistiska och nysakliga typografi. Samarbetet mellan Eva och Anders Billow skedde i båda riktningarna. Eva diskuterade sina skisser och utkast med Anders. Problem och lösningar avhandlades och ofta utformades detaljer gemensamt (Behrens 1962, 10). Eva utförde ofta teckningar till Anders bokprodukter när en titel eller ett omslag snarare krävde en kalligrafisk än en typografisk lösning 


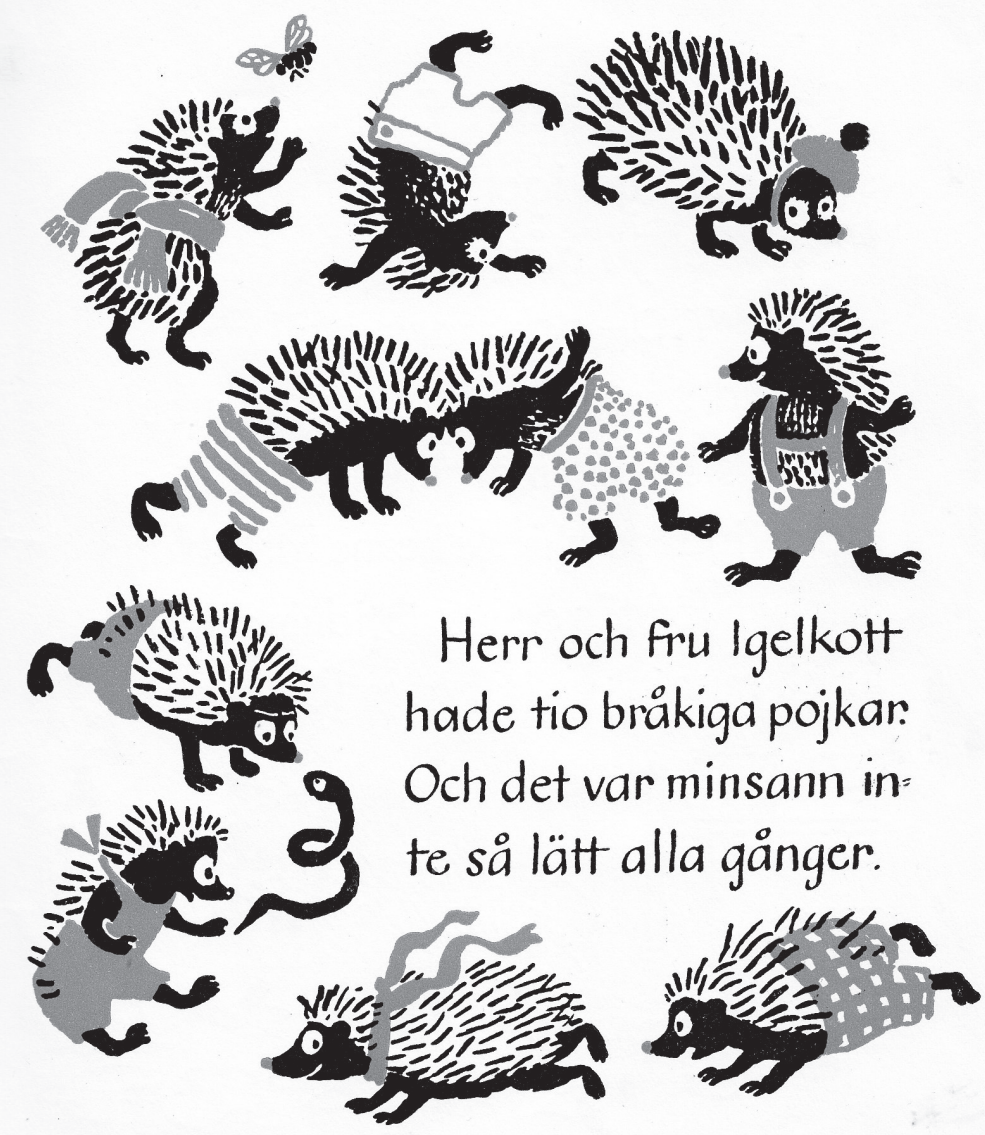

III. I (C) Eva Billow. Pojkarna Igelkotts vinterskor. Stockholm: Nordisk rotogravyr, 1948.

(Behrens, 10). Paret arbetade dessutom flera gånger för samma uppdragsgivare, bl.a. Nordisk rotogravyr samt de inflytelserika folkrörelserna Svensk Turistförening och Kooperativa Förbundet. Trots att Eva och Anders Billows samarbete närmast helt ignorerats i tidigare forskning är det en essentiell del av hennes konstnärliga utveckling och yrkesidentitet. Eva Billows fleråriga samarbete med Nordisk rotogravyr, ledd av Simon Söderstam och med Anders Billow som konstnärlig ledare, är likaså betydelsefull för hennes yrkesroll. 


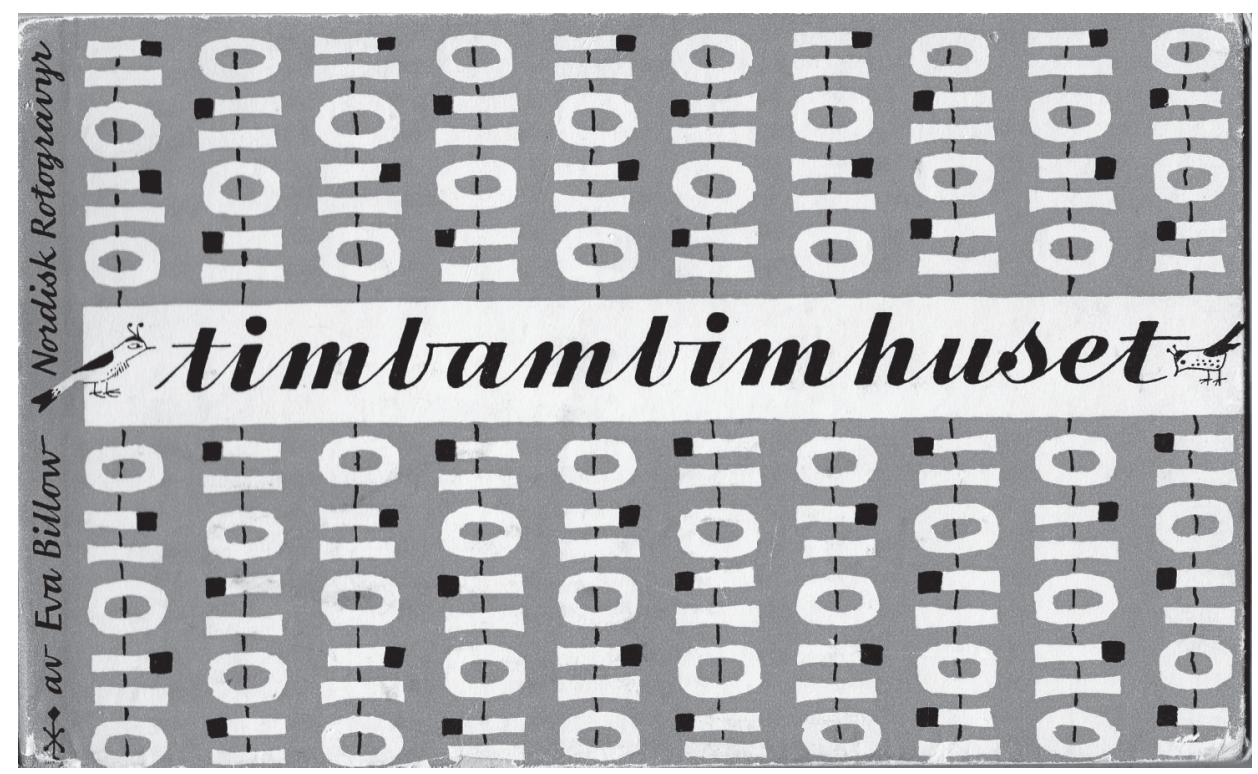

III. 2 @ Eva Billow. Timbambimhuset. Stockholm, Nordisk rotogravyr, 1955.

Tryckeriet var känt för sin förstklassiga bokformgivning liksom för sin förlagsverksamhet (Gram 2006, 55).

\section{Form och funktion}

Att boken på alla plan formas efter sin funktion och innehåll uttrycks bland annat i hur Billow arbetar med storlek och format. Dessa egenskaper är grundläggande för bilderbokens yttre karakteristik, men påverkar även berättelsens dimensioner och såväl textens som bildernas omfattning och uttryck. Många av bilderböckerna under 1950-talet var relativt små, vilket ofta kan ses som en särskild anpassning till barnets behov och storlek (bl.a. Christensen 2003, s. 82). Hos Billow handlar det lilla formatet, liksom valet av det liggande eller stående formatet, också om formmässig koncentration. Formatet väljs för att passa den specifika boken och dess motiv.

I bilderboken Pojkarna Igelkotts vinterskor (1948) ger bokens format upphov till en formmässig reducering och en möjlighet att fokusera små detaljer. Det kvadratiska formatet, som har mindre rörelseenergi än rektangeln, används för att skapa en upplevelse av trängsel i igelkottsfamiljen med tio busiga pojkar. Bildelementen, satsytan och typografin vävs samman till en konstnärlig helhet där text- och bildinnehåll korresponderar (Ill. 1). Medan det cirkulära 
rörelsemönstret och det kvadratiska rummet upprepas i alla interiörscener i Pojkarna Igelkotts vinterskor används det liggande tvärformatet genomtänkt i Timbambimhuset (1955). Den långa och rytmiska, närmast tungvrickande titeln framhävs dessutom genom att ordet placeras löpande över det liggande omslaget. När boken öppnas fördubblas bokens liggande längd, något som Billow utnyttjar i sin layout och färgsättning. Det avlånga, liggande formatet tillåter ett helt annat rumsperspektiv. Handlingen i Timbambimhuset tar plats i Afrika, och handlar om lejonungen Tim och barnen Bim och Bam. De träffas och bestämmer sig att göra "allting som vi inte får, men ingenting som vi får". Lejonungen som fått tillåtelse av sina föräldrar att äta upp den lilla pojken bestämmer sig för att leka med honom i stället och Bim klappar lejonet, något han varnats för. Fokus ligger på barnens lek, minspel och kroppsspråk. Billow växlar mellan dynamiska och statiska motiv och kompositioner. Inom ett uppslag skildras grässtrån, tistlar och små insekter i förgrunden av bildrummet samtidigt som det skapas en upplevelse av långt avstånd till horisonten i bildens övre del. Utnyttjandet av marginalerna och utfallande bilder och färgfält används för att skapa ett slags panoramaformat i miniatyr (Ill. 2).

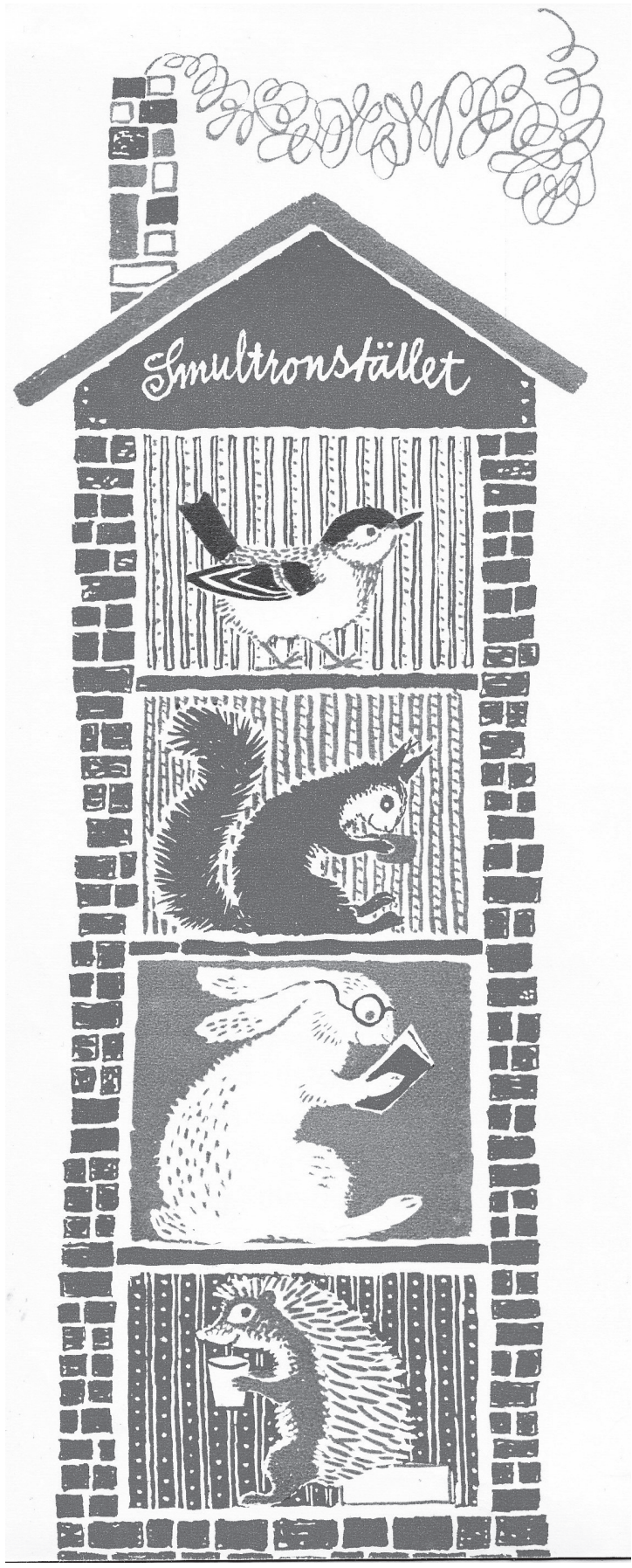

III. 3 @ Eva Billow. Hittar du till smultronstället? Stockholm: Nordisk rotogravyr, 1954. 
Även i Hittar du till Smultronstället? (1954) speglar formatet bokens händelseförlopp. Boken kan ses som en lekfull kommentar till den rådande bostadsbristen och det följande uppsvinget $\mathrm{i}$ bostadsbyggandet i Sverige under 1950-talet. Berättelsen handlar nämligen om Herr Humlelöv som bygger ett fyravåningshöghus för djuren. I detta "smultronställe" flyttar en igelkott, kanin, ekorre och talgoxe in. Men så händer någonting rysligt: huset tippar och faller med en skräll. Hyresgästerna upptäcker att de nu i stället bor i ett radhus! Huset som följer bokens stående format, ligger nu på tvären, över båda sidhalvorna, vilket ändrar hela uppslagets komposition. Den lilla berättelsen om Herr Humlelövs bostadsbygge exemplifierar väl hur bokens fysiska form och attribut som storlek, format och layouten, fungerar som bärare av budskap och uttryck. Hur dimensionerna med det ambitiösa höghusbygget speglas i formatet uttrycker ett förhållningssätt till bokformgivning där bokens syfte - i det här fallet också motivet - får styra formgivningen (Ill 3).

Eva Billow arbetade med uttryck och tekniker som både ingår i och omförhandlar bilderbokens och bokformgivningens traditioner. Förutom en funktionalistisk syn på boken, där boken formas som ett instrumentellt system där bilderna och de typografiska elementen framför allt skulle formas efter sitt syfte, är det läsandet och samspelet mellan ord och bild och form som sätts i centrum hos Billow. Hennes bilderböcker exemplifierar därmed bilderbokens förhållande till andra visuella medier och inte minst till den grafiska formgivningens och bokkonstens utveckling. Detta perspektiv öppnar för nya tolkningar gällande Eva Billows produktion men nyanserar förhoppningsvis också bilden av bilderbokens modernism i Sverige.

Den nyorientering som sker inom svensk bilderbok under 1940och 1950-talen rymmer flera utvecklingslinjer. Tendensen med bilderböcker, ofta skapade i samarbete med bildkonstnärer, och i flera fall med kopplingar till Danmark, är förmodligen tydligast och mest uppmärksammad. Bilderboken ses här somen plats för experimentell, modernistisk estetik eller ett sätt att förmedla konst till barnen. Eva Billows bilderböcker kan inte helt naturligt inkluderas i denna grupp, här uttrycks inte samma upproriska och oppositionella attityd som i exempelvis Hellsings barnböcker. Målet är ett annat, att samtidigt som den grafiska formgivningen och bokkonsten förnyas, modernisera bilderbokens formspråk. Billow visar genom sin produktion en ambition att anknyta bokkonsten och konsthantverket, det vill säga att sammansmälta konsten och konsthantverket till en enhet. Därmed exemplifierar hennes illustrationskonst bilderboksmediets 
utveckling i förhållande till en dynamisk period inom grafisk formgivning i Europa och Sverige. Billow uttrycker en vilja att utforska bilderbokens estetik i modernistisk anda, att hitta ett bildspråk och uttryck för en ny tid, ett bildspråk som präglas av lätthet, stramhet och ändamålsenlighet.

Biografisk information: Elina Druker är forskare i litteraturvetenskap vid Stocholms universitet. I sin avhandling Modernismens bilder: den moderna bilderboken i Norden (2008) undersökte Druker bilderbokens modernism under 1940- och 1950-talen. Hon arbetar för närvarande med ett post doc-projekt om bilderbokskonstnären Eva Billow, finansierad av Anna Ahlströms och Ellen Terserus stiftelse. Kontakt: elina.druker@littvet.su.se

\section{Bibliografi}

Behrens, Charles G.L. "Eva Billows exlibris". I Svenska exlibrisföreningens årsbok 1961-1962. Stockholm: Svenska exlibrisföreningen, 1962, 9-22.

Bergstrand, Ulla. "Eva Billow". I De läses än: från Louisa Alcott till Erik Zetterström A-L. Lund: Bibliotekstjänst, 1992.

Bergstrand, Ulla. "Eva Billow, bilderbokskonstnär". I Barnboken. 1985:2, 34-36.

Billow, Eva. Hittar du till smultronstället? Stockholm: Nordisk rotogravyr, 1954.

Billow, Eva. Timbambimhuset. Stockholm, Nordisk rotogravyr, 1955.

Billow, Eva. Pojkarna Igelkotts vinterskor. Stockholm: Nordisk rotogravyr, 1948.

Bolin, Greta. Recension av God morgon och godnatt. I Svenska Dagbladet, 1951.

Bolin, Greta. Recension av Jag tycker mest om plättar. I Svenska Dagbladet, 1953.

Bolin, Greta. "Vackert, vänligt och lustigt för de små". I Svenska Dagbladet, 1954.

Bolin, Greta. Recension av Ta av dig mössan, Mårten!. I Svenska Dagbladet, 1957.

Christensen, Nina. Den danske billedbog 1950-1999: teori, analyse, historie.

Danmarks pædagogiske universitet, Center for Børnelitteratur. Frederiksberg : Roskilde Universitetsforlag, 2003.

Corinna, [Greta Bolin]. "Eva Billow, en idylliker med artisteri barnbok". Svenska Dagbladet, 1961.

Druker, Elina. Modernismens bilder: den moderna bilderboken i Norden. Diss., Stockholms universitet. Skrifter utgivna av Svenska barnboksinstitutet, 103. Göteborg \& Stockholm: Makadam, 2008. 
Dusinberre, Juliet. Alice to the lighthouse: children's books and radical experiments in art. Basingstoke, London: Macmillan, 1987.

Gram, Magdalena. "När typografin blev 'modern': om modernismens genombrott i svensk typografi". Biblis (2006) 34: 51-63.

Hellsing, Lennart. Tankar om barnlitteraturen. Stockholm: Rabén \& Sjögren, 1963/1999.

Hellsing, Lennart. Recension av Godmorgon och godnatt. Aftonbladet, 1951.

Lloyd, Rosemary. The land of lost content: children and childhood in nineteenth-century french literature. Oxford: Clarendon press, 1992.

Magnusson, Helena. Berättande bilder: svenska tecknade serier för barn. Diss., Stockholms universitet. Skrifter utgivna av Svenska barnboksinstitutet, 89. Göteborg \& Stockholm: Makadam, 2005.

Mathiesen, Egon. Moderne bogillustration. Köpenhamn: Rasmus Naver, 1934.

Schlyter, Brita. "Bilderböcker och pyssel". Dagens Nyheter, 1954.

Stybe, Vibeke. "En verden fuld af billeder". I Dansk børnelitteraturhistorie. Red. Kari Sønsthagen \& Lena Eilstrup. København: Høst \& søn, 1992.

Wellsjö, Eva. "Eva Billow - den typografiska barnboksmästarinnan". I Barnboken (1992:1), 34-36.

Westin, Boel. "Mission impossible: barnlitteraturforskningens dilemma". I Läsebok: en festskrift till Ulf Boëthius 2/12 1993, red. Carina Lidström. Skrifter utgivna av Svenska barnboksinstitutet, 48. Stockholm: B. Östlings bokförlag Symposion, 1993.

Westin, Boel. "Superbarn, vardagsbarn och vilda bebisar: svenska bilderböcker 1945-1980". I I bilderbokens värld. 1880-1980. Stockholm: LiberFörlag, 1985, s. 61-72.

Wickman, Karin (red.). Formens rörelse: svensk form genom 150 år. Stockholm: Carlsson, 1995.

Wollin, Nils G. Hemmet och den moderna smaken i Sverige. Stockholm, 1928.

von Zweigbergk, Eva. "Årets bilderböcker". Dagens Nyheter, 1949.

von Zweigbergk, Eva. "Barnens syn på bilderböckerna". Dagens Nyheter, 1953.

Note: This article is being published simultaneously in Barnboken - tidskrift för barnlitteraturforskning/Journal of Children's Literature Research and Nordic ChildLit Aesthetics/Barnelitterart forskningstidsskrift 